\title{
Properties of surface engineered metallic parts prepared by additive manufacturing
}

\author{
Stelzer Nils ${ }^{1}$, Sebald Torsten ${ }^{2}$, Hatzenbichler Markus ${ }^{3}$, Bonvoisin Benoit ${ }^{4}$, L'uboš Bača ${ }^{1}$, \\ Scheerer Michael ${ }^{1}$
}

\begin{abstract}
The potential of the Additive Manufacturing technologies is impeded by the surface finish obtained on the as-manufactured material. Therefore, the influence of various surface treatments, commonly applied to space hardware, on the mechanical properties of three selected metallic alloys (SS316L, AlSi10Mg, Ti6Al4V) prepared by using Selective Laser Melting (SLM) and Electron Beam Melting (EBM) additive manufacturing processes have been investigated. Within this study, SLM using EOS M400 and EOS M280 equipment and in addition EBM using an ARCAM Q20 machine have been applied for sample manufacturing. A half-automated shot-peening process followed by a chemical and/or electrochemical polishing or Hirtisation ${ }^{\circledR}$ process has been applied in order to obtain lower surface roughness compared to their as-received states. Special emphasize has been taken on their tensile, fatigue, and fracture toughness properties. In addition, their stress corrosion cracking (SCC) behaviour including microstructural analysis using HR-SEM have been investigated.
\end{abstract}

\section{Keywords}

Additive Manufacturing, Ti6Al4V, SS316L, AlSi10Mg, mechanical properties, Stress corrosion, Surface post- processing, space environment

\section{Introduction}

Additive manufacturing technologies allow manufacture of shapes that are not possible with conventional machining. This design freedom is very attractive for space hardware, as equipment performance could be significantly improved with increased shape complexity. Furthermore, conventional machining results in a high buy-to-fly ratio; i.e. more than $70 \%$ of the material is transformed to swarf, which has to be recycled. Using additive manufacturing, the amount of material to be recycled is substantially decreased, limited to the light structure that may be needed to support the part while it is built. The potential of the Additive Manufacturing technologies is however impeded by the surface finish obtained on the asmanufactured 3D objects. Especially inner surfaces of additive manufactured complex shaped parts became difficult or all but impossible to reach by conventional machining processes. Recently, surface finishing processes have been developed enabling not only the surface finish of complex outer but also inner structures of AM parts, e.g. Abrasive Flow Machining by Micro Technica $^{\circledR}$ Technologies GmbH, ALMBrite ${ }^{\mathrm{TM}}$ by South West Metal Finishing, MMP Technology ${ }^{\circledR}$ by BinC Industries SA, 3DSurFin ${ }^{\circledR}$ by Airbus Defence and Space GmbH or the Hirtisation process by Hirtenberger Surface Engineering GmbH (HES). Within this study an extensive survey of surface finishing processes has been performed taking various relevant factors for space hardware (surface roughness, cleanliness, costs, process stability, 
accessability, etc.) into account. An assessment lead to the selection of surface finishing processes and combination thereof for three selected metallic alloys (SS316L, A1Si10Mg, Ti6Al4V) prepared by Selective Laser Melting (SLM) and in case of Ti6Al4V also by Electron Beam Melting (EBM). Here we will report on static and dynamic mechanical properties of above mentioned alloys and manufacturing processes after application of the selected surface finishing processes. In addition, the AM alloys have been tested according to their resistance against stress corrosion cracking (SCC).

\section{Experimental}

\subsection{Materials and manufacturing}

The raw materials have been supplied for SS316L and A1Si10Mg by Electro Optical Systems GmbH. The Ti6Al4V powder has been acquired from TLS Technik GmbH \& Co. Spezialpulver KG.

The SS316L and Ti6A14V samples have been manufactured by SLM using an EOS M280 machine. In case of Ti6Al4V, in addition an Arcam A2X for EBM has been applied. The AlSi10Mg samples have been manufactured using an EOS M400 machine. The AlSi10Mg and Ti6Al4V as-build samples have been heat treated directly after manufacturing using a Carbolite thermal vacuum oven.

\subsection{Surface finishing methods}

The following Tab. 1 will give an overview of the different surface finishing scenarios applied to the materials/manufacturing combinations. All samples are shot peened in a first step. In a second and/or third step chemical and/or electrochemical polishing has been applied. In case of AlSi10Mg a patented surface finishing process by Hirtenberger Surface Engineering has been applied.

\section{Table 1: Surface finishing scenarios applied to different materials/AM processes}

\begin{tabular}{|c|c|c|}
\hline Material/AM process & $\begin{array}{l}\text { Heat } \\
\text { treatment }\end{array}$ & Surface finishing scenario \\
\hline SLM SS316L & $\begin{array}{l}\text { No heat } \\
\text { treatment }\end{array}$ & $\begin{array}{l}\text { 1. Shot peening } \\
\text { 2. Electrochemical polishing }\end{array}$ \\
\hline SLM Ti6Al4V & $\begin{array}{l}800^{\circ} \mathrm{C}, 4 \mathrm{~h}, \\
\text { Argon }\end{array}$ & $\begin{array}{l}\text { 1. Shot peening } \\
\text { 2. Chemical polishing }\end{array}$ \\
\hline EBM Ti6Al4V & $\begin{array}{l}800^{\circ} \mathrm{C}, 4 \mathrm{~h}, \\
\text { Argon }\end{array}$ & $\begin{array}{l}\text { 1. Shot peening } \\
\text { 2. Chemical polishing } \\
\text { 3. Electrochemical polishing }\end{array}$ \\
\hline SLM AlSi10Mg & $\begin{array}{l}250^{\circ} \mathrm{C}, 2 \mathrm{~h}, \\
\text { air }\end{array}$ & $\begin{array}{l}\text { 1. Shot peening } \\
\text { 2. HES process }\end{array}$ \\
\hline
\end{tabular}

\subsection{Characterization methods}

Static Tensile tests have been performed according to ASTM E8-04 using an universal testing machine type Shimadzu AGC-10/TC with a maximum load of $100 \mathrm{kN}$ for each of the material/manufacturing combinations in the three principal directions in as received and in surface finished conditions. Five parallel samples have been used. Flat samples in $\mathrm{x}$ and $45^{\circ}$ direction (relative to the building surface) and round samples have been used in z-direction. Out of the tests the Young's Modulus, $0.2 \%$ proof strength $\mathrm{R}_{\mathrm{p} 0.2}$, ultimate tensile strength $\mathrm{R}_{\mathrm{m}}$ (UTS) and strain to failure $\mathrm{A} \%$ have been determined. 
Fatigue tests have been performed in a servo-hydraulic testing machine for each of the material / manufacturing combinations in the weakest direction out of the static tensile tests in as received and in optimized surface finished conditions. Four different load levels on 3 parallel samples have bene used. The proposed sample shape $(\mathrm{Kt}=2.3)$ allows testing at any $\mathrm{R}$ value ( $\mathrm{R}=0.1$ in this study) and allows the assessment of the effectiveness of the surface finishing procedure also at inner surfaces, such as holes. Out of the tests, a reduced Woehler curve for each material in as received and optimized surface finished conditions can be determined. All fractured samples have been subjected to an investigation of the fracture surface by high resolution scanning electron microscopy HRSEM/ZEISS - Gemini Supra VP equipped with EDAX - EDS/EBSD - Detectors in order to determine the starting point of final fracture and possible presence of micro-pores.

Fracture toughness tests have been performed in a universal testing machine type Shimadzu AGC-10/TC with online CTOD (crack tip open displacement) measurement for each of the material / manufacturing combinations in the strongest and weakest direction out of the static tensile tests in optimized surface finished conditions. 5 parallel samples have been used. Precracking of the samples to achieve the required total crack length has been done by fatigue loading with online CTOD measurement in the servo-hydraulic testing machine. Based on a first assessment of the required dimensions for valid K1C evaluation - based on available material data for conventional materials and standard ASTM E399 no of the investigated alloys fulfil the requirements. For AISI 316L it is not possible to manufacture the required dimensions of more than $1000 \mathrm{~mm}$. Therefore, in all cases where the requirements for direct assessment of K1C according to ASTM E399 are not fulfilled, fracture toughness values based on J-Integral evaluation (ASTM 1820) are used. All fractured samples have been subjected to an investigation of the fracture surface by scanning electron microscopy in order to determine the starting point of final fracture and possible presence of micro-pores.

The aim of the stress corrosion testing according to ECSS-Q-70-37C is to assess the susceptibility to stress corrosion cracking (SCC) of the material / manufacturing combinations in as received condition and with its selected best surface treatment procedures.

Surface roughness measurements have been performed for as received and surface finished samples according to ISO 4287-1997 on the side and top surface. The average and standard deviation of the Ra- (average mean of the profile height) and Rz-value (average maximum height of the profile) were calculated from these measurements.

\section{Results}

\subsection{Tensile test results}

The tensile behaviour and tensile properties - Young's Modulus, Yield strengths, tensile strength and strain to failure - has been determined for the 4 different materials / AM manufacturing method combinations before and after surface treatment according to ASTM E8-04 for vertical, horizontal and $45^{\circ}$ samples. The tensile properties of AISi10Mg manufactured by SLM are shown in Figure 1. The Yield strength (Rp0.2) shows an anisotropy behaviour regarding build-up orientation of samples where the weakest direction was the vertical (185 MPa) and the strongest the horizontal one with the value of $201 \mathrm{MPa}$. On the other hand the tensile strength and the strain to failure shows the opposite behaviour where the strongest direction was the vertical (355 MPa and 4.3\%) and weakest direction the horizontal one (319 MPa and 3.5\%). It has to be mentioned that the sample shapes for the vertical (round) differ from that of the horizontal (flat) and $45^{\circ}$ (flat) ones, which could have an influence on the anisotropy of the tensile strength - usually the vertical direction shows the lowest strength. The anisotropy behaviour was not changed by the surface treatment, but values for Yield 
strength and tensile strength were slightly improved. No statistically relevant changes in the strain to failure after surface treatment have been observed.
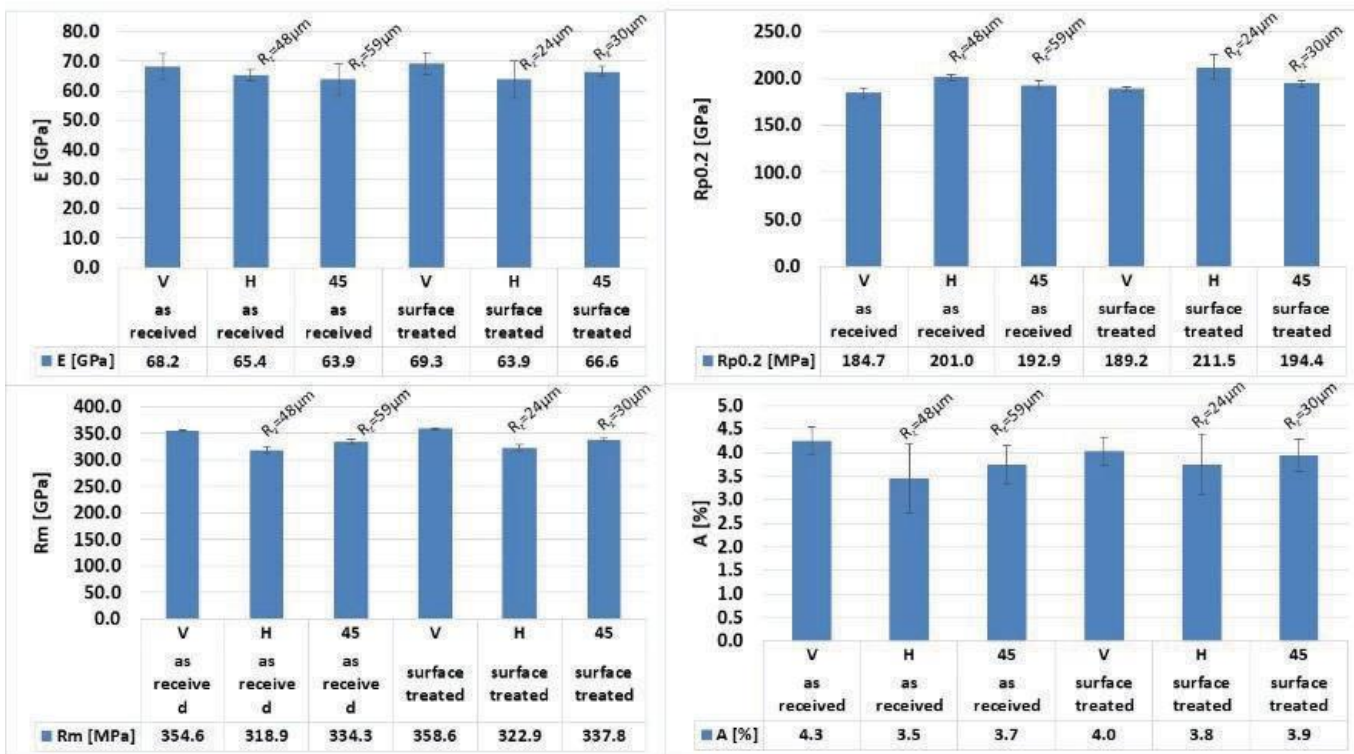

Figure 1: Summary of tensile parameters for AISi10Mg

The tensile properties of AISI 316L manufactured by SLM are shown in Figure 2. The Yield strength and tensile strength show an anisotropy behaviour regarding the building strategy. The lowest values of UTS and Rp0.2 (543MPa and $428 \mathrm{MPa})$ were observed for vertical direction while the highest for samples built in the horizontal direction (614 MPa and $506 \mathrm{MPa}$ ). As expected, the strain to failure shows the opposite behaviour with the highest ductility in the vertical and the lowest ductility in the horizontal direction. The anisotropy behaviour was not changed by the surface treatment. Again the surface treatment improved the Yield strength about $10.7 \%$ in vertical and $3.3 \%$ in horizontal direction as well as tensile strength about $1.5 \%$ in vertical and $3.7 \%$ in horizontal direction. No statistically relevant changes in the strain to failure after surface treatment have been observed.

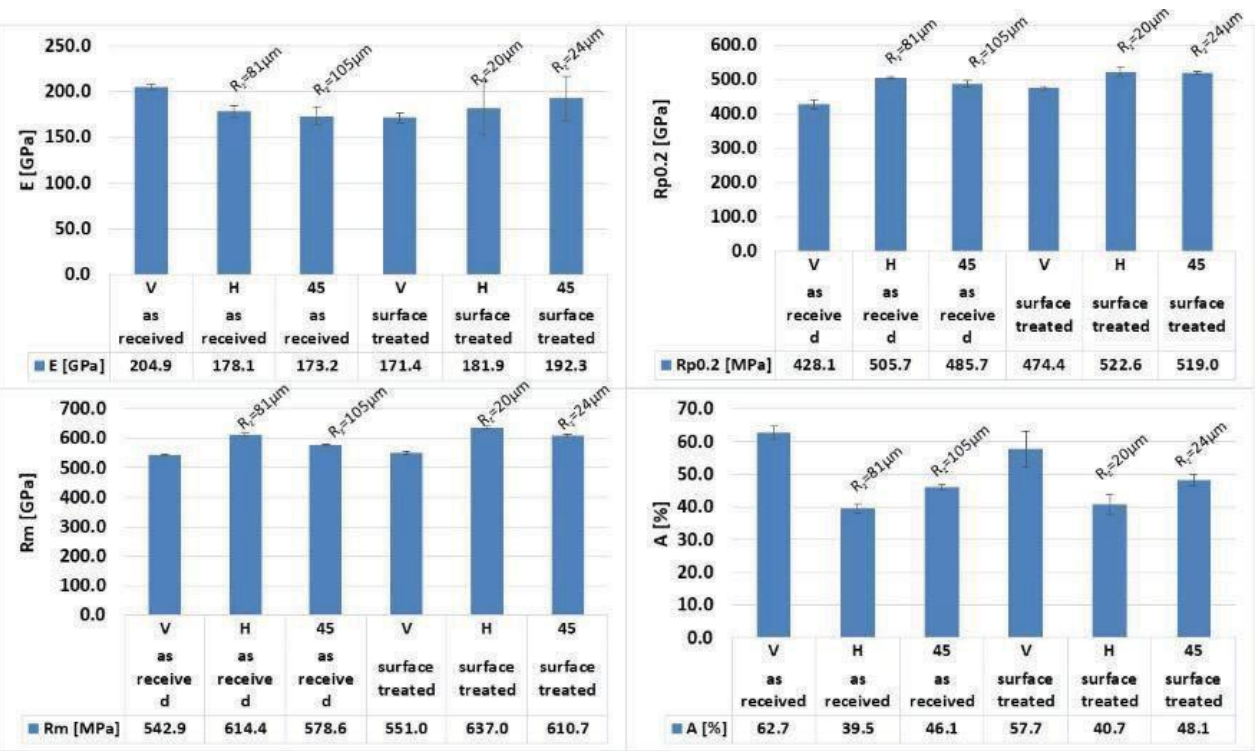

Figure 2: Summary of tensile parameters for AISI 316L 
The tensile properties of Ti6Al4V manufactured by SLM are shown in Figure 3. The results of UTS and Yield strength revealed very low anisotropy of measured specimens thus being independent on the manufacturing strategy. The highest strengths values were observed for samples built-up in $45^{\circ}$ direction $(984 \mathrm{MPa})$. The strain to failure shows the highest ductility for the vertical and lowest ductility for the horizontal direction. The anisotropy behaviour was not changed by the surface treatment. After surface treatment the values for Yield strength and tensile strength were slightly increased. No statistically relevant changes in the strain to failure after surface treatment have been observed.
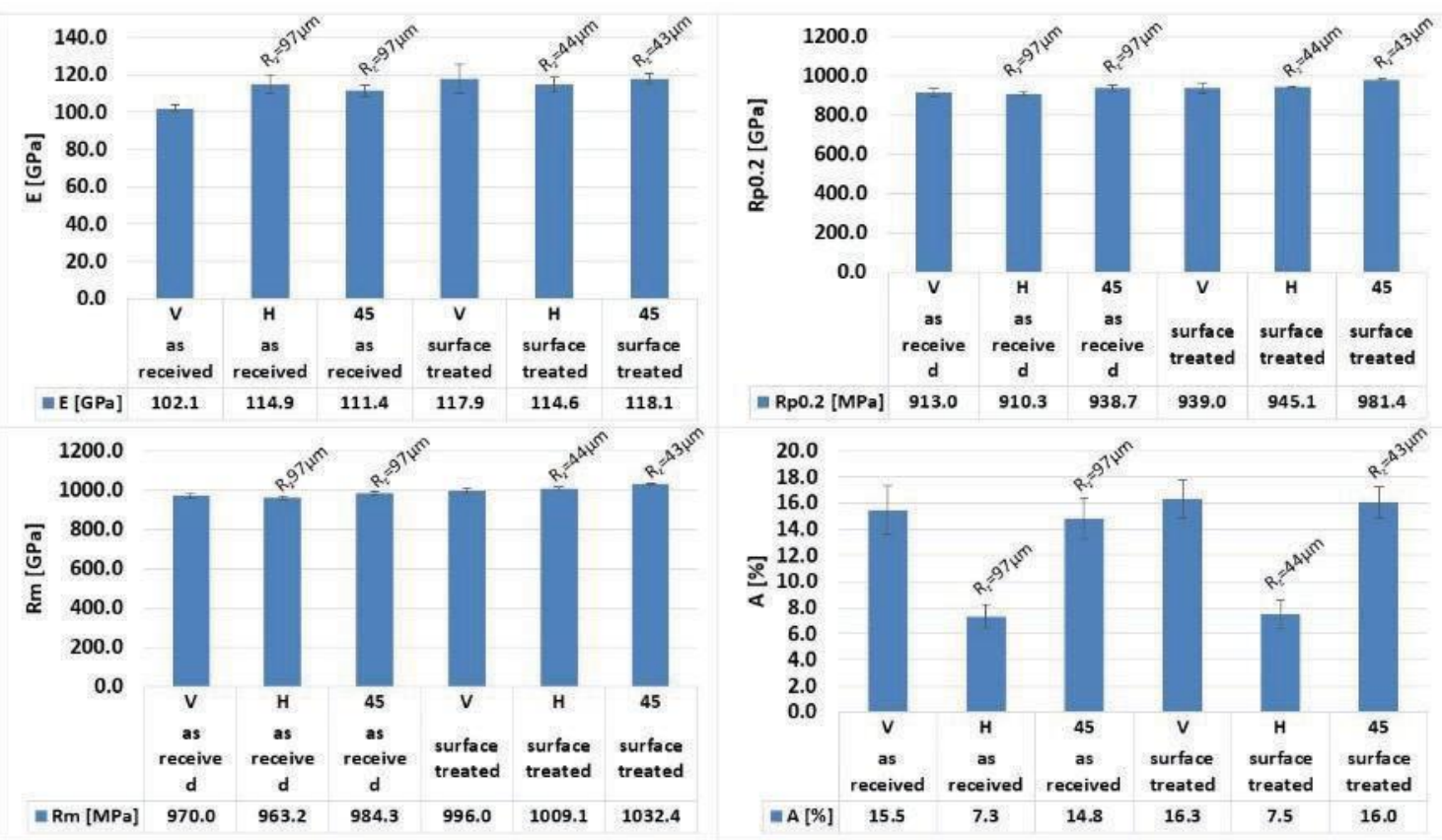

Figure 3: Summary of tensile parameters for Ti6AI4V / SLM

The tensile properties of Ti6Al4V manufactured by EBM are shown in Figure 4. In comparison to the SLM process, the UTS, Rp0.2 and the strain to failure decreased with higher anisotropy behaviour. The highest UTS of $877 \mathrm{MPa}$ was obtained for the vertical direction and the lowest UTS for horizontally aligned samples (792 MPa).
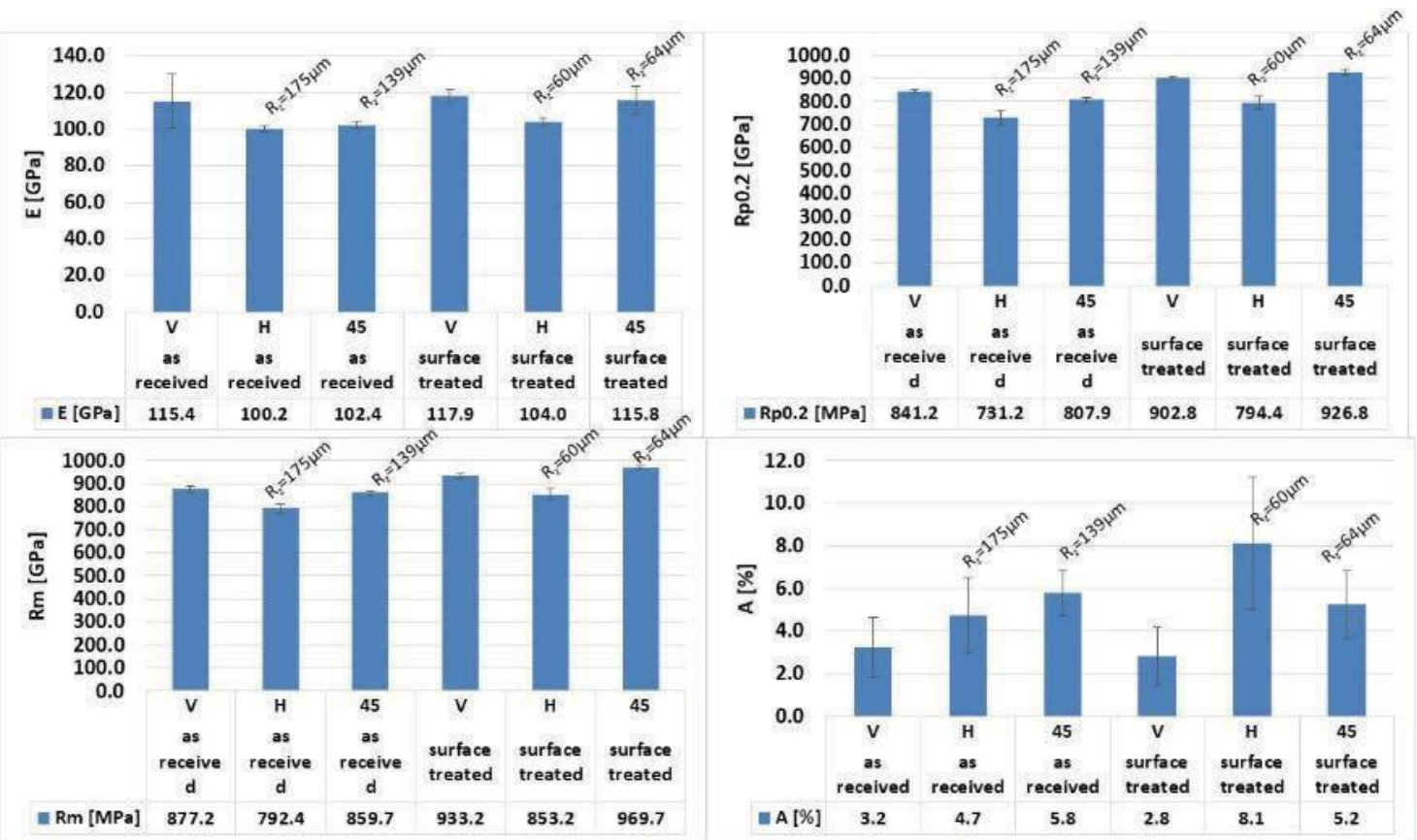

Figure 4: Summary of tensile parameters for Ti6Al4V / EBM 
In general, the strengths values and strain to failure was rather low compared to SLM Ti6A14V samples. The anisotropy behaviour was not changed by the surface treatment. After surface treatment the values for Yield strength and UTS were slightly increased. No statistically relevant changes in the strain to failure after surface treatment has been observed except for the horizontal direction were the strain to failure was nearly doubled.

The following Figure 5 shows the fractured areas of horizontal and vertical tensile specimens. It can be seen that areas of voids with un-molten powder particles are present in the fractured surface. These defects were found in nearly all EBM specimens (also in the fatigue samples). In addition, the cross section of the flat specimens were not rectangular (see upper right side of Figure 5) leading to an overestimation of the measured cross section and subsequent underestimation of the strength values of the flat specimens in horizontal and $45^{\circ}$ direction. The root cause for these internal defects is not clear yet.
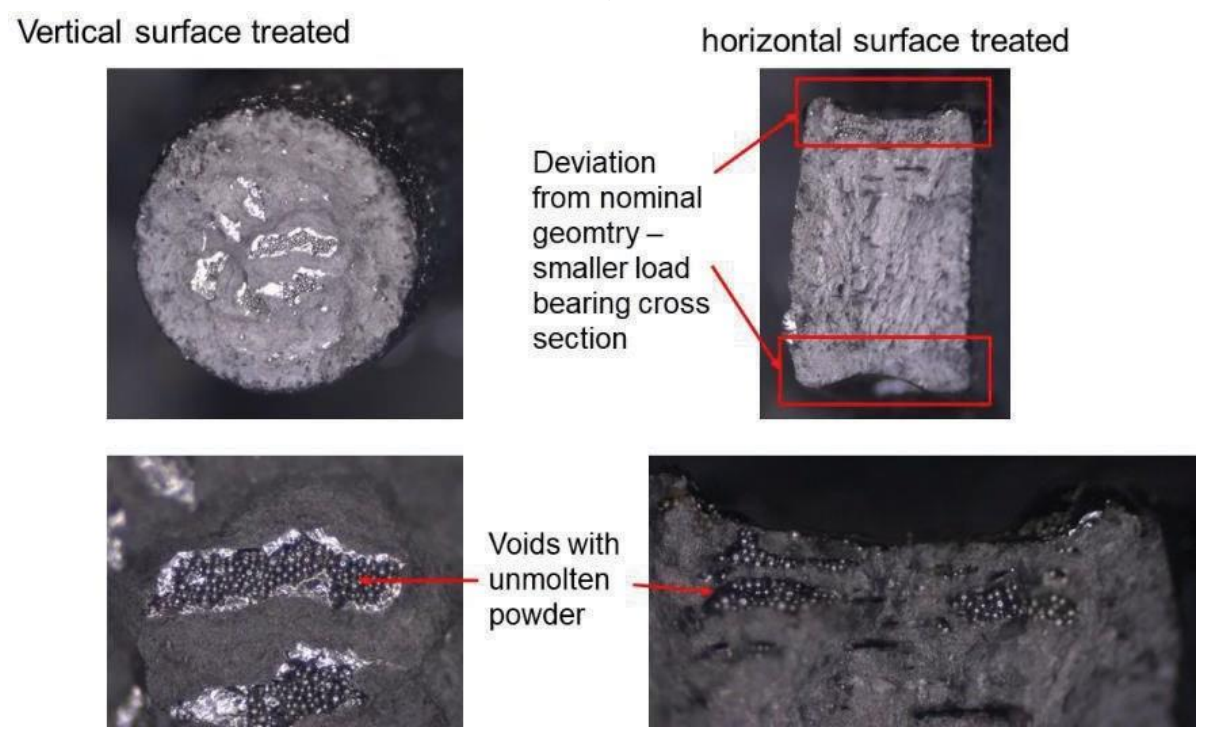

Figure 5: Fracture areas of examples of the horizontal and vertical tensile specimens

\section{Fatigue results}

In order to assess the influence of the surface roughness on the load bearing cross section, all strength data of the fatigue tests were corrected using the average $\mathrm{R}_{\mathrm{z}}$ values measured before. The following sketch (see Figure 6) shows the used method for the correction of the

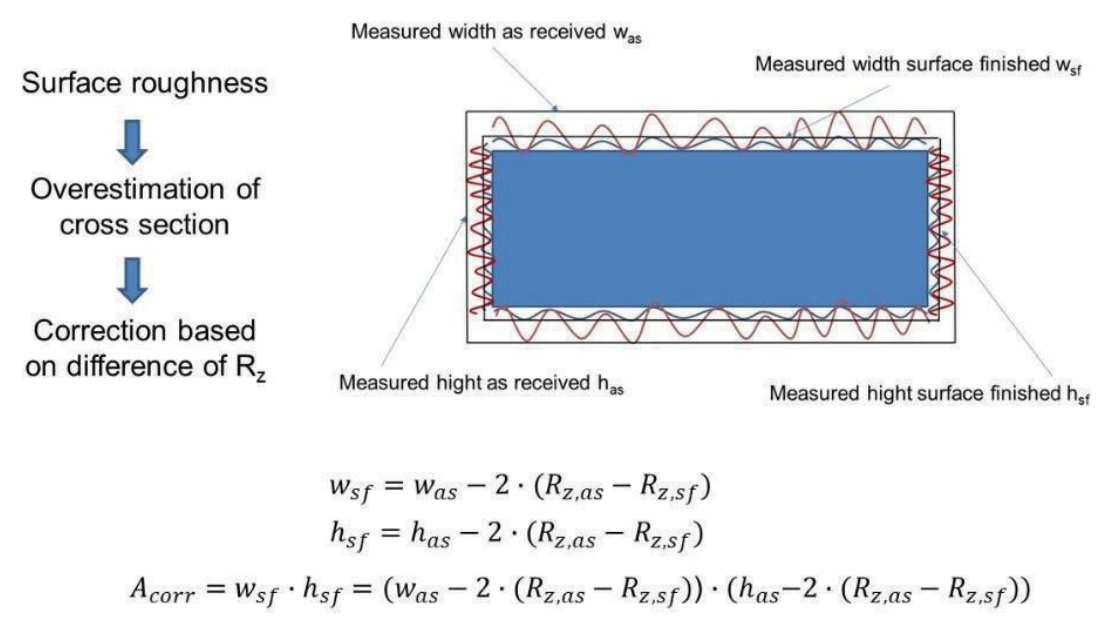

Figure 6: Used method for the correction of the measured cross section using the Rz values of the as received specimens and the $\mathrm{Rz}$ values of the surface finished samples 
measured cross section using the $\mathrm{R}_{\mathrm{z}}$ values for the as-received specimens and the $\mathrm{R}_{\mathrm{z}}$ values of the surface finished samples. The method has been applied for all fatigue samples. The following figures show the Woehler curves of the as-received, surface finished and corrected as-received samples (red bars) for all investigated materials.

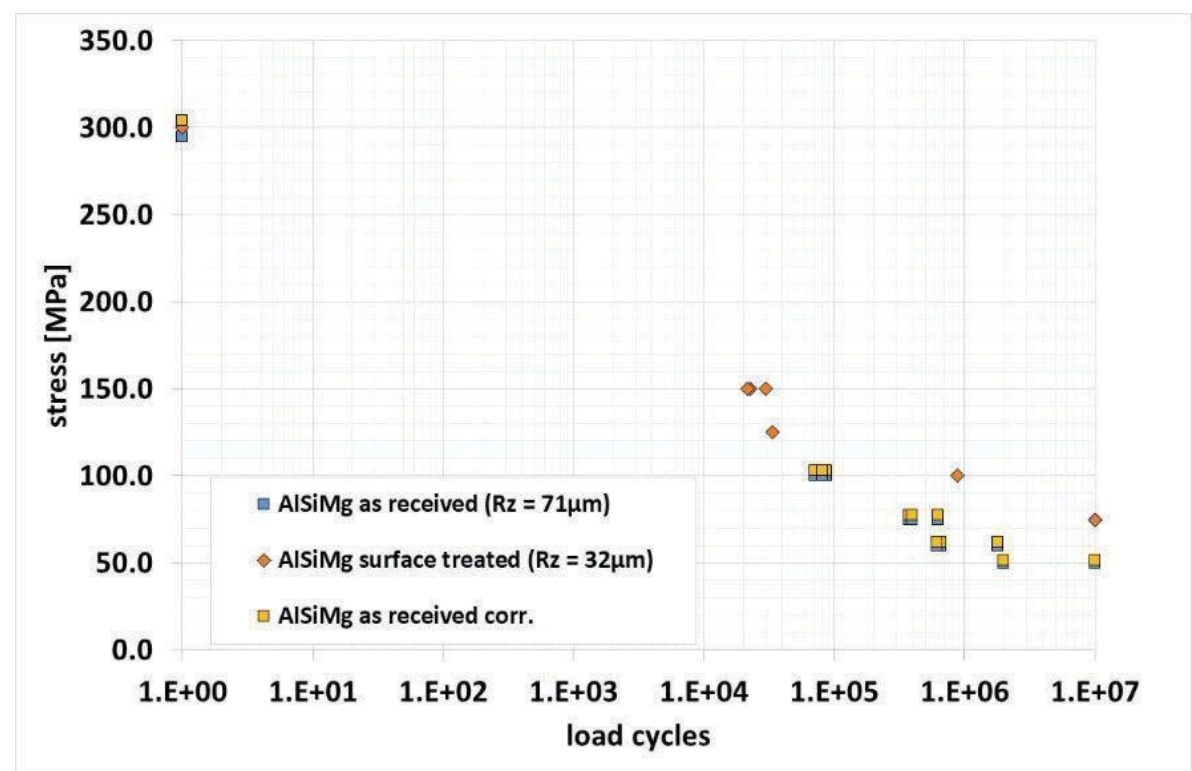

Figure 7: Woehler curves of the as received, surface finished and corrected as received samples (red bars) for AlSi10Mg

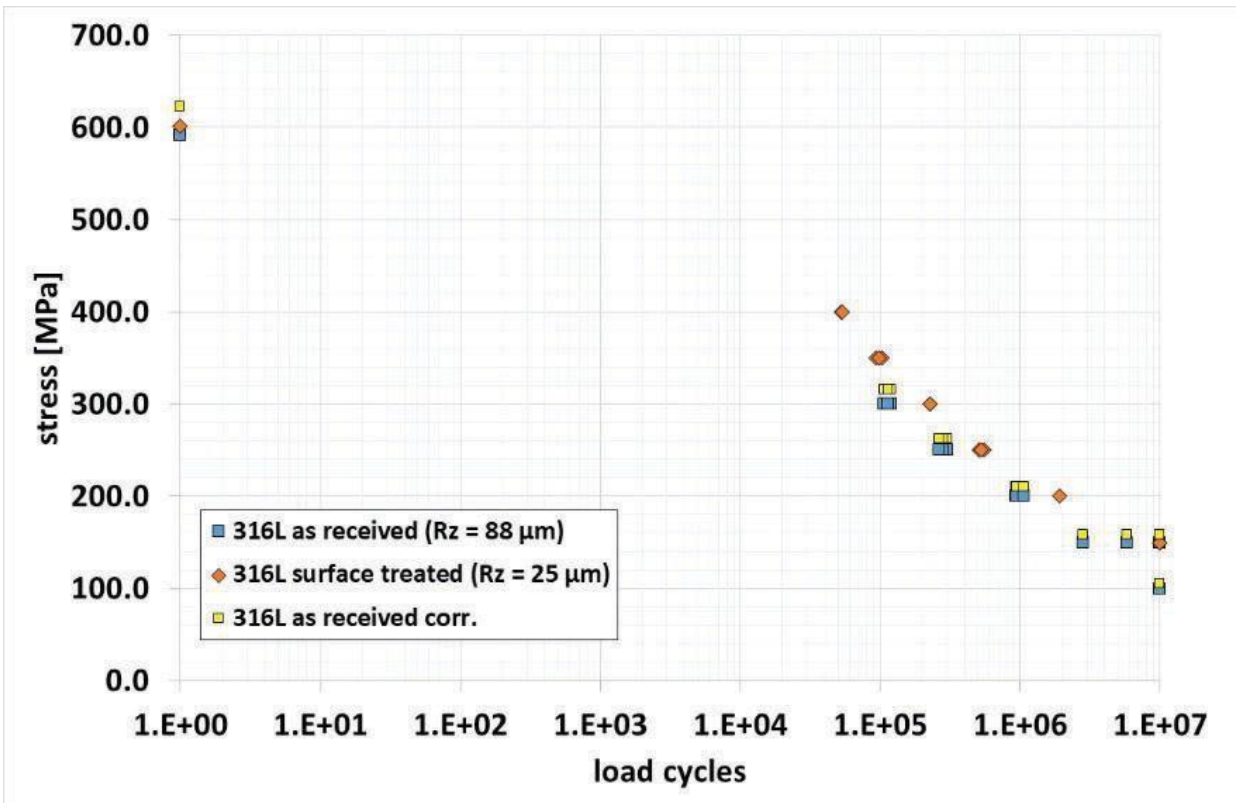

Figure 8: Woehler curves of the as received, surface finished and corrected as received samples (red bars) for $316 \mathrm{~L}$ 


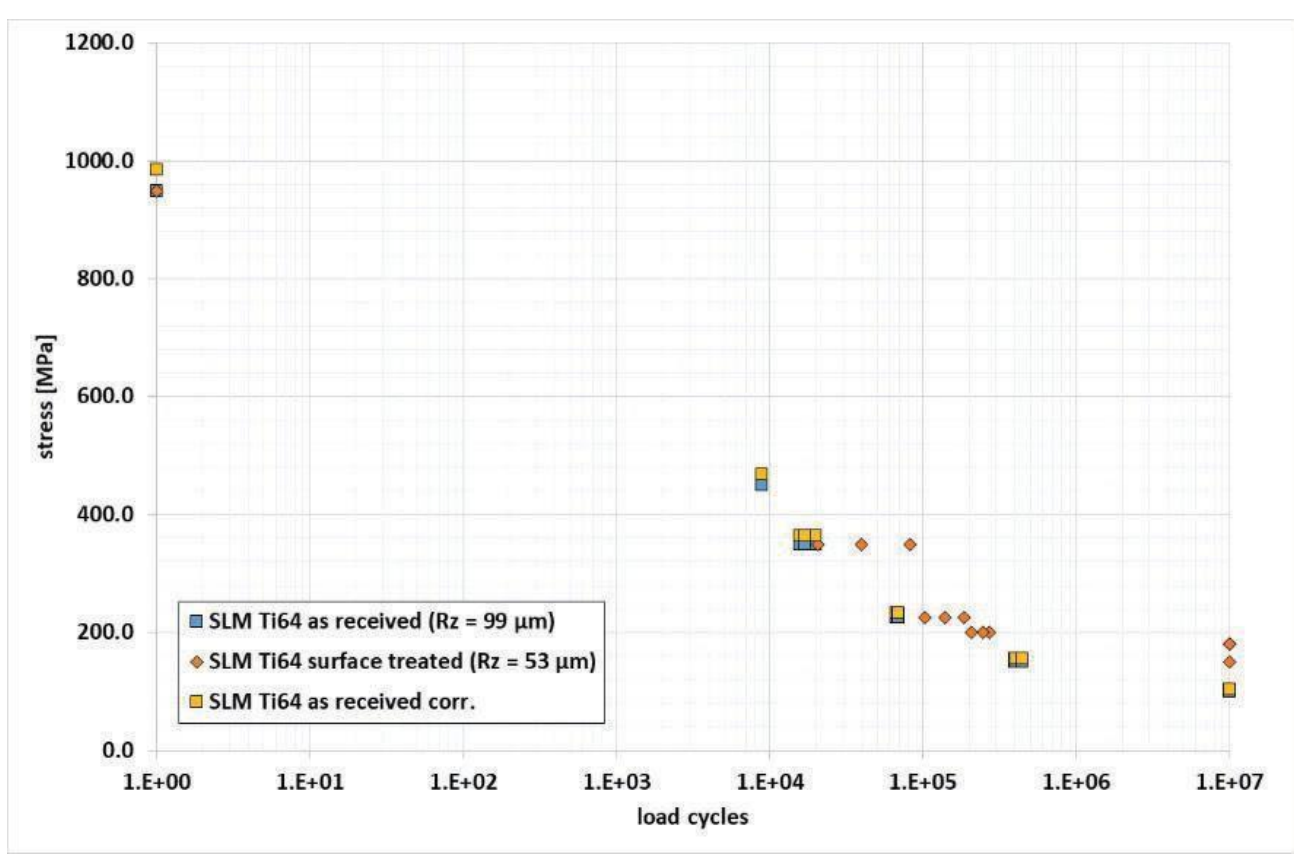

Figure 9: Woehler curves of the as received, surface finished and corrected as received samples (red bars) for SLM Ti64

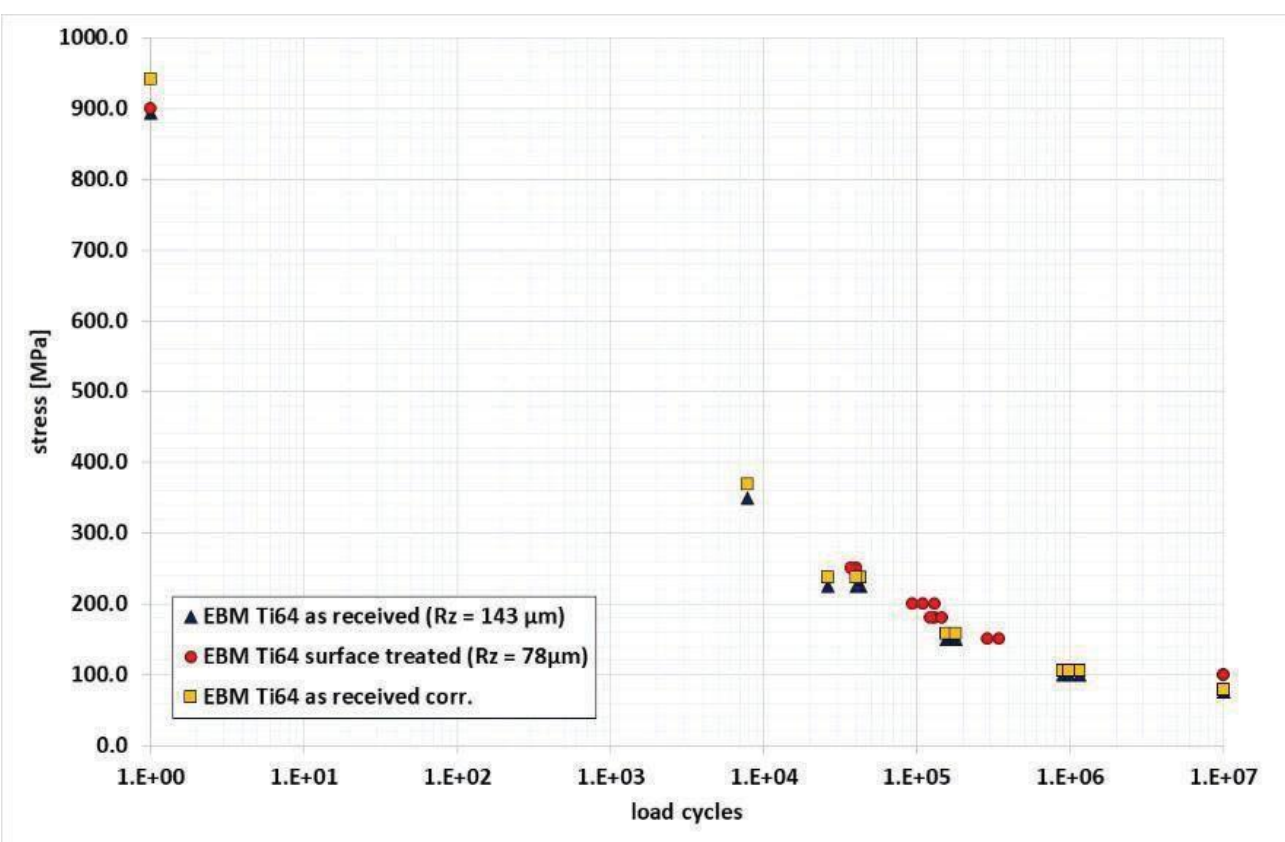

Figure 10: Woehler curves of the as received, surface finished and corrected as received samples (red bars) for EBM Ti64

It can be seen, that the surface roughness correction led to a slight increase of the strength values for all materials, but in all cases the surface finishing procedure lead to clear increase in the fatigue strength values well above the corrected values. The following Table 2 shows the fatigue live strength $\left(\mathrm{N}>10^{7}\right.$ load cycles for all materials in as received and surface finished conditions). In Table 3 the surface roughness and the corresponding improvements for each material/process after the individual surface finishing scenarios is shown. 
Table 2: Fatigue live strength $\left(\mathrm{N}>10^{7}\right.$ load cycles) for all materials

\begin{tabular}{|c|c|c|c|}
\hline Material & Condition & Fatigue live [MPa] & $\begin{array}{c}\text { Increase of fatigue } \\
\text { live [\%] }\end{array}$ \\
\hline \multirow{2}{*}{ AlSi10Mg } & As received & 50 & 50 \\
\cline { 2 - 3 } & SP + CHP +EP & 75 & \multirow{2}{*}{33} \\
\cline { 2 - 3 } AISI 316L & As received & 112.5 & \multirow{2}{*}{70} \\
\cline { 2 - 3 } & SP + CHP +EP & 150 & \multirow{2}{*}{33} \\
\cline { 2 - 3 } SLM Ti64 & As received & 100 & 170 \\
\hline \multirow{2}{*}{ EBM Ti64 } & SP + CHP & 75 & \multicolumn{2}{|c}{} \\
\cline { 2 - 4 } & SP + CHP + EP & 100 & \\
\hline
\end{tabular}

Table 3: Surface roughness and the corresponding improvements after the individual surface finishing scenarios

\begin{tabular}{|l|l|l|l|l|l|l|l|}
\hline & & $\mathrm{Ra}[\mu \mathrm{m}]$ & $\mathrm{Ra}[\mu \mathrm{m}]$ & $\mathrm{Ra}$ & $\mathrm{Rz}[\mu \mathrm{m}]$ & $\mathrm{Rz}[\mu \mathrm{m}]$ & $\mathrm{Rz}$ \\
\hline Material & Scenario & $\begin{array}{l}\text { As } \\
\text { received }\end{array}$ & $\begin{array}{l}\text { Surface } \\
\text { finished }\end{array}$ & $\%$ & As received & $\begin{array}{l}\text { Surface } \\
\text { finished }\end{array}$ & $\%$ \\
\hline AlSi10Mg & SP + CHP +EP & $8.88 \pm 1.26$ & $5.50 \pm 0.36$ & 38 & $55.39 \pm 5.67$ & $29.61 \pm 2.02$ & 47 \\
\hline AISI316L & SP + CHP +EP & $14.71 \pm 0.95$ & $4.42 \pm 0.44$ & 70 & $88.58 \pm 4.80$ & $23.06 \pm 3.07$ & 74 \\
\hline SLM Ti64 & SP + CHP & $16.12 \pm 1.22$ & $7.27 \pm 0.71$ & 55 & $96.39 \pm 6.75$ & $40.56 \pm 3.40$ & 58 \\
\hline EBM Ti64 & SP + CHP + EP & $28.89 \pm 2.13$ & $13.78 \pm 1.22$ & 52 & $157.85 \pm 10.52$ & $71.84 \pm 6.83$ & 54 \\
\hline
\end{tabular}

\section{Fracture toughness results}

All fracture mechanic tests have been performed in surface finished conditions. However, the influence of the surface finishing on the fracture mechanic properties is considered very limited. The following figures show the calculated KJC values for all materials. No statistical relevant differences were found in the KJC values in horizontal and vertical building direction. The values are in expected ranges of conventional materials.

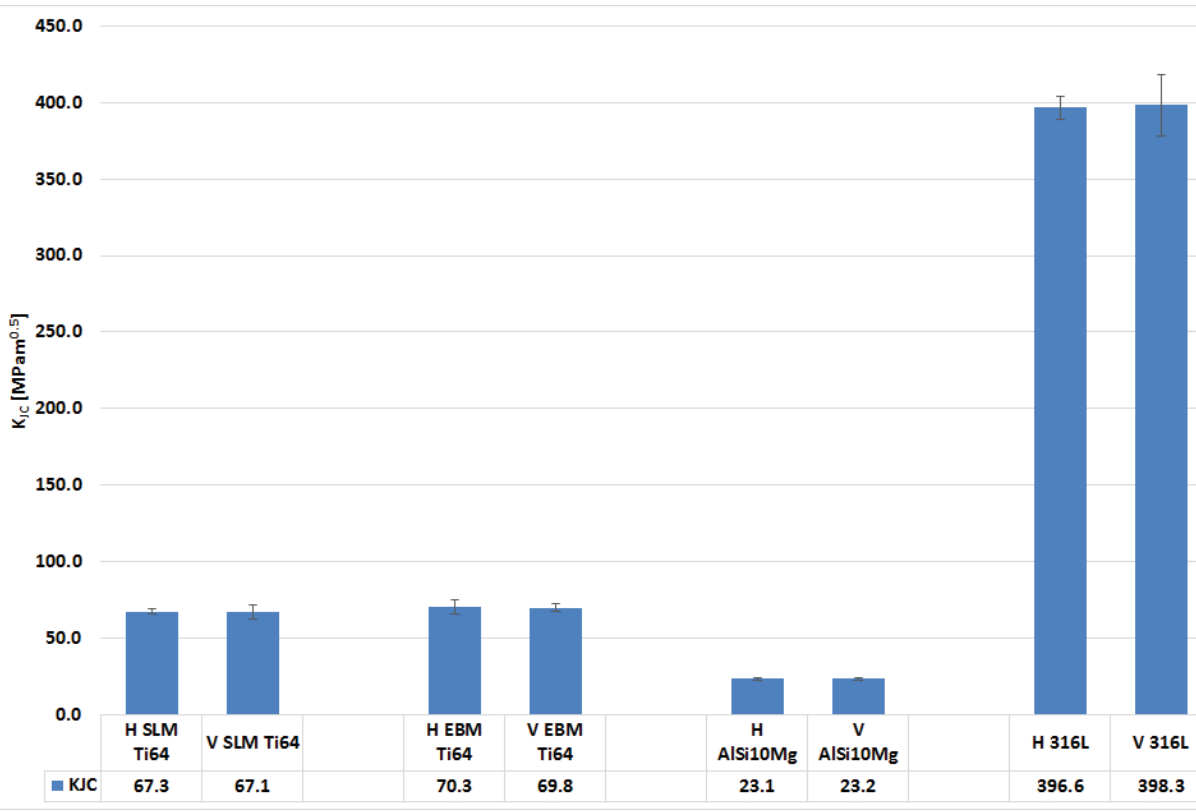

Figure 11: Calculated KJC values for all materials 


\section{Susceptibility to Stress Corrosion Cracking}

The SCC behaviour has been determined for the 4 different material / AM manufacturing method combinations before and after surface treatment. The tests were carried out in accordance to the standard ECSS-Q-70-37C. The results are shown in Table 4. All 4 materials passed the test according to the standard.

Table 4: Summary of SCC tests

\begin{tabular}{|c|c|c|c|c|c|c|}
\hline Material & Condition & $\mathbf{R}_{\mathbf{m}, \text { reference }}$ & $\mathbf{R}_{\mathrm{m}, \mathrm{SCC}}$ & $\mathbf{R}_{\mathbf{m} \text {,control }}$ & Metallography & $\begin{array}{l}\text { SCC- } \\
\text { Class }\end{array}$ \\
\hline \multirow[t]{2}{*}{ AlSi10Mg } & $\begin{array}{l}\text { As } \\
\text { received }\end{array}$ & 348 & 288 & 320 & $\begin{array}{l}\text { surface corrosion and partly strongly } \\
\text { localized, "crack-like" corrosion, } \\
\text { no typical signs of SCC phenomenon }\end{array}$ & (A)-B \\
\hline & $\begin{array}{l}\text { Surface } \\
\text { finished }\end{array}$ & 352 & 310 & 305 & $\begin{array}{l}\text { surface corrosion and partly strongly } \\
\text { localized, "crack-like" corrosion, } \\
\text { no typical signs of SCC phenomenon }\end{array}$ & (A)-B \\
\hline \multirow[t]{2}{*}{3161} & $\begin{array}{l}\text { As } \\
\text { received }\end{array}$ & 551 & 545 & 543 & $\begin{array}{l}\text { no signs of corrosion and SCC } \\
\text { phenomenon }\end{array}$ & $\mathbf{A}$ \\
\hline & $\begin{array}{l}\text { Surface } \\
\text { finished }\end{array}$ & 567 & 565 & 565 & $\begin{array}{l}\text { no signs of corrosion and SCC } \\
\text { phenomenon }\end{array}$ & $\mathbf{A}$ \\
\hline \multirow[t]{2}{*}{ SLM Ti64 } & $\begin{array}{l}\text { As } \\
\text { received }\end{array}$ & 955 & 993 & 941 & no signs of SCC phenomenon & $\mathbf{A}$ \\
\hline & $\begin{array}{l}\text { Surface } \\
\text { finished }\end{array}$ & 1,000 & 996 & 974 & $\begin{array}{l}\text { nascent surface corrosion, no signs of } \\
\text { SCC phenomenon }\end{array}$ & $\mathbf{A}$ \\
\hline \multirow[t]{2}{*}{ EBM Ti64 } & $\begin{array}{l}\text { As } \\
\text { received }\end{array}$ & 864 & 822 & 853 & $\begin{array}{l}\text { no corrosion signs, no signs of SCC } \\
\text { phenomenon }\end{array}$ & $\mathbf{A}$ \\
\hline & $\begin{array}{l}\text { Surface } \\
\text { finished }\end{array}$ & 893 & 871 & 899 & $\begin{array}{l}\text { no corrosion signs, no signs of SCC } \\
\text { phenomenon }\end{array}$ & $\mathbf{A}$ \\
\hline
\end{tabular}

\section{Acknowledgement}

The study presented was supported by the ESA GSTP programme. ESA Contract No. 4000114710 15NL SFe.

\section{REFERENCES}

[1] R. Chatterjee-Fischer, Internal oxidation during carburizing and heat treating. Metallurgical transactions A 9A (1978) 1553-1560.

[2] I. Gibson, D.W. Rosen, B. Stucker, 2015, Additive Manufacturing Technologies: 3D Printing, Rapid Prototyping, and Direct Digital Manufacturing, Springer, pp. 1-498.

[3] L. Dreval, T. Zienert, O. Fabrichnaya, Calculated phase diagrams and thermodynamic properties of the $\mathrm{Al} 2 \mathrm{O} 3-\mathrm{Fe} 2 \mathrm{O} 3-\mathrm{FeO}$ system. Journal of alloys and compounds 657 (2016) 192-214.

[4] J. H. Swisher and E. T. Turkdogan, Solubility, permeability, and diffusivity of oxygen in solid iron.Trans. Metall. Soc. AIME 239 (2018) 426-431.

[5] J. Takada, S. Yamamoto, S. Kikuchi, M. Adachi, Determination of diffusion coefficient of oxygen in $\gamma$-iron from measurements of internal oxidation in $\mathrm{Fe}-\mathrm{Al}$ alloys. Metallurgical transactions A 17 (2018) 221-229.

[6] Bourell, D., et al., Materials for additive manufacturing. CIRP Annals, 2017. 66(2): p. 659-681.

[7] A. Staub, A.B. Spierings, K. Wegener, Correlation of meltpool characteristics and residual stresses at high laser intensity for metal lpbf process, Adv. Mater. Process. Technol. 5 (2019) 153-161.

[8] Y. Wang, J. Shi, Y. Liu, Competitive grain growth and dendrite morphology evolution in selective laser melting of Inconel 718 superalloy, J. Cryst. Growth 521 (2019) 15-29. 